Aims: Evaluation of long-term growth in relation to standard intake with low and higher amount of amino acids (AA), Ca, $P$.

Methods: consecutive cohort study (C1, C2) preterm infants with follow up until 24 months; standard parenteral intake: C1: $\max : 2.5 \mathrm{~g} / \mathrm{kg} / \mathrm{d}$ AA, Ca/P: 1/0,26 mmol/kg/d C2: $\operatorname{max:~} 3 \mathrm{~g} / \mathrm{kg} / \mathrm{d}$ AA, Ca/P: $3 / 1,9 \mathrm{mmol} / \mathrm{kg} / \mathrm{d}$. Enteral feeding: not different, starting day 1 ; human milk fortification from 50ml/d on. Comparison between two cohorts: nutritional intake and growth during first five weeks, follow up at term corrected age (TCA), 6, 12 and 24 months. SDS for weight and length according to Dutch reference1,2.

Results: C1: Male: $\mathrm{n}=28, \mathrm{GA} 29.3 \pm 2.3$, BW 1272 \pm 351g. Female $n=29$ GA28.8 \pm 1.7 , BW 1129 \pm 319 C2: Male: $n=35$ GA 29.5 \pm 1.9 , BW 1325 \pm 359 , Female $n=30$, GA $29.4 \pm 3.6$, BW $1272 \pm 340$

\begin{tabular}{|l|l|l|l|l|l|l|l|l|l|}
\hline $\begin{array}{l}\text { Mean } \\
\text { SDS }\end{array}$ & $\begin{array}{l}\text { Birth } \\
\text { weight }\end{array}$ & $\begin{array}{l}\text { TCA } \\
\text { weight }\end{array}$ & $\begin{array}{l}6 \mathrm{~m} \\
\text { weight }\end{array}$ & $\begin{array}{l}12 \mathrm{~m} \\
\text { weight }\end{array}$ & $\begin{array}{l}24 \mathrm{~m} \\
\text { weight }\end{array}$ & $\begin{array}{l}\text { TCA } \\
\text { length }\end{array}$ & $\begin{array}{l}6 \mathrm{~m} \\
\text { length }\end{array}$ & $\begin{array}{l}12 \mathrm{~m} \\
\text { length }\end{array}$ & $\begin{array}{l}24 \mathrm{~m} \\
\text { length }\end{array}$ \\
\hline C1Fem & 0.11 & -1.9 & -0.5 & -0.6 & -0.5 & -3.0 & -0.5 & -0.6 & -0.5 \\
\hline C2Fem & 0.15 & -2.2 & -0.8 & -0.6 & -0.5 & -2.7 & -0.3 & -0.5 & -0.5 \\
\hline C1Male & 0.53 & -1.5 & -0.7 & -0.6 & -0.5 & -2.6 & -0.2 & -0.2 & -0.2 \\
\hline C2Male & 0.36 & -1.2 & -0.4 & -0.5 & -0.4 & -1.8 & 0.1 & -0.1 & 0.0 \\
\hline
\end{tabular}

[Table 1 SDS for weight and length]

Conclusions: AGA infants demonstrated main catch up at 6 months after TCA with complete recovery for length in $\mathrm{C} 2$ male. Male infants take more advantage from improved feeding regimen.

1. Visser GHA Early Hum Dev 2009

2. Frederiks AM Ped Res 2000

1059

BODY COMPOSITION OF ADEQUATE AND SMALL FOR GESTATIONAL AGE NEWBORNS AND THE RELATIONSHIP WITH MATERNAL BODY COMPOSITION

J.S. Camelo, Jr ${ }^{1}$, J.P. Monteiro ${ }^{1}$, J.S. Marchini², E. Ferriolli ${ }^{2}$, K. Pfrimer ${ }^{1}$, G. Duarte ${ }^{3}$, L.M. Traver ${ }^{1}$, A.M. Sanche $z^{4}$, T. Oliveira ${ }^{4}$, F.E. Martinez ${ }^{1}$

${ }^{1}$ Pediatrics, ${ }^{2}$ Internal Medicine, ${ }^{3}$ Gynecology and Obstetrics, ${ }^{4}$ Nutrition and Metabolism, University of São Paulo, Ribeirão Preto, Brazil

Introduction: Low birth weight and intrauterine growth restriction are associated to high morbidity and mortality. A compromised maternal nutritional status and placental failure could be responsible for intrauterine growth insufficiency.
Objective: To describe mothers' body composition of adequate for gestational age (AGA) and small for gestational age (SGA) newborn infants, and to correlate them with newborns' body composition.

Methods: 19 term AGA newborns and 18 term SGA newborn were studied. Anthropometric data was registered. The body composition of mothers and their respective babies was determined by deuterium dilution and analyzed by gas isotopic ratio mass spectrometry and bioelectrical impedance analysis (BIA).

Results: There was no difference in anthropometric characteristics and body composition between AGA and SGA mothers. There was a strong correlation between the two methods utilized for analysis of maternal body composition (deuterium vs BIA). Gestational age, gender distribution and Apgar score were similar between AGA and SGA babies. AGA newborns showed higher weight and length at birth and study period, as well as higher Rohrer index, cephalic, thoracic and braquial circumpherence, triciptal and subscapular skinfolds, compared to SGA newborns. There was a significant difference in body composition between AGA and SGA groups regarding fat mass $(13,5 \% \pm 4,80$ AGA vs $7,01 \%$ $\pm 3,41$ SGA) and total body water $(74,4 \% \pm 2,73$ SGA vs. $68,3 \% \pm 4,51 \mathrm{AGA})$. It was not found any significant correlation between maternal and newborn's body composition in both groups.

Conclusion: Intrauterine growth restriction is not related to maternal body composition in our university hospital.

1060

\section{EATING, DRINKING AND SWALLOWING DISORDERS: A NEW REGIONAL CLINIC REVIEW}

\section{P. Gallagher, F. Sharif}

\section{Paediatrics, Midland Regional Hospital, Mullingar, Ireland}

Background: Eating, drinking and swallowing (EDS) disorders can have serious consequences for children which include dehydration, malnutrition, failure to thrive, aspiration pneumonia, choking and possibly death. Paediatric feeding disorders have been reported in up to $25 \%$ of children. This number increases to $80 \%$ in developmentally delayed children. Therefore disordered feeding should involve assessment by a multidisciplinary team. 